\title{
Interaction of the Microtubule-Associated Host Protein HIP2 with Viral Helper Component Proteinase Is Important in Infection with Potato virus A
}

\author{
Tuuli Haikonen, Minna-Liisa Rajamäki, and Jari P. T. Valkonen \\ Department of Agricultural Sciences, P.O. Box 27, FI-00014, University of Helsinki, Finland
}

Submitted 22 January 2013. Accepted 22 February 2013.

\begin{abstract}
Microtubules (MT) outline and maintain the overall shape of cells and can reorganize cellular membranes to serve as sites of RNA virus replication. Here, we provide data on involvement of an MT-associated protein in infection of plants with a potyvirus, Potato virus $A$ (PVA), representing the largest family of plant-infecting RNA viruses. Our results showed that helper-component proteinase (HCpro)interacting protein 2 (HIP2) of potato (Solanum tuberosum) is an MT-associated protein similar to Arabidopsis SPR2. Virus-induced silencing of HIP2 in Nicotiana benthamiana resulted in a spiral-like growth phenotype, similar to the Arabidopsis spr2 mutant, and the spr2 phenotype in Arabidopsis was complemented with potato HIP2. HCpro of PVA interacted with HIP2 of potato and tobacco (Nicotiana tabacum). The interaction was detected by bimolecular fluorescence complementation in PVA-infected leaves on MT and MT intersections at the cell cortex. HIP2-HCpro interaction was determined by the $C$-proximal $\alpha$-helix-rich domain of HIP2, whereas the N-proximal putative TOG domain and the central coiled-coil domain of HIP2 controlled HIP2 dimerization and binding to MT. Accumulation of PVA was significantly reduced in the HIP2-silenced leaves of $N$. benthamiana, which indicates that HIP2HCpro interactions are important for virus infection.
\end{abstract}

Microtubules (MT) define and maintain the overall shape of cells, mark the position of the cell plate at cell division, and separate sister chromatids in mitosis and homologous chromosomes in meiosis (Hawkins et al. 2010). MT are composed of a lattice of $\alpha$ and $\beta$ tubulin heterodimers that stack end to end to form protofilaments that, in turn, bind laterally to form sheets that are rolled into a hollow tube. Heterodimers can associate to or dissociate from either end of MT. The more dynamic, faster growing and shrinking end capped with $\beta$ subunits is called a (+)-end. Although MT are dynamic and able to polymerize and depolymerize rapidly at their free ends, they are

Nucleotide sequence data is available in the National Center for Biotechnology Information database under accession numbers HE649915 for NtHIP2 and HE653966 for StHIP2.

Corresponding author: J. P. T. Valkonen; Telephone: +358-9-19158387; Fax: +358-9-19158727; E-mail: jari.valkonen@helsinki.fi

* The $e$-Xtra logo stands for "electronic extra" and indicates that eight supplementary figures, two supplementary tables, and a supplementary movie are published online.

C 2013 The American Phytopathological Society also the most rigid filaments of the intracellular cytoskeleton and provide a firm support for attachment of actin and myosin (Hawkins et al. 2010).

In plants, MT are organized mostly as a cortical MT array consisting of coaligned or bundled MT. They attach to actin filaments, the plasma membrane, and endomembranes at multiple sites via MT-associated proteins or protein complexes located along the MT, the MT-ends, or both (Ambrose and Wasteneys 2012; Cai 2010). Plants seem to employ actin filaments and the endomembrane system for intracellular transport (Cai and Cresti 2010). These routes and mechanisms are also utilized by plant viruses (Harries et al. 2010; Schoelz et al. 2011). However, plant viruses may interact with MT to reorganize the endoplasmic reticulum (ER) for the purpose of virus replication. For RNA viruses, this occurs on the ER and other membranes (Miller and Krijnse-Locker 2008). A few recent reports have indicated that the tobamoviruses Tobacco mosaic virus and oilseed rape mosaic virus (a synonym or alternative name for Youcai mosaic virus; Zhu et al. 2001) and Potato mop-top virus (family Virgaviridae) can regulate MT dynamics and organization and that virus-MT interactions influence virus movement or accumulation (Ashby et al. 2006; Ouko et al. 2010; Ruggenthaler et al. 2009; Wright et al. 2010). Nevertheless, little is known about the role of MT in plant virus infections and thus further study is required.

The family Potyviridae comprises the largest group of positive-strand RNA viruses infecting plants, including approximately 200 confirmed or tentative virus species that cause yield losses in crop plants. Potyviruses contain an open reading frame (ORF) encoding a large polyprotein subsequently processed into up to 10 mature proteins by viral proteinases and an additional shorter, $5^{\prime}$-proximal ORF created by frameshifting and producing an additional protein (Adams et al. 2012; Chung et al. 2008; Vijayapalani et al. 2012; Wei et al. $2010 \mathrm{~b})$. The helper component proteinase (HCpro) is a multifunctional protein that cleaves the polyprotein at the C-terminus of HCpro and is involved in virus multiplication, cell-tocell movement, and suppression of RNA silencing-based antiviral defense in plants (Rajamäki et al. 2004). HCpro interacts with many host proteins (Ala-Poikela et al. 2011) such as the HCpro-interacting protein 2 (HIP2) of potato (Solanum tuberosum; family Solanaceae) (Guo et al. 2003). Interaction of HIP2 with the HCpro of Potato virus A (PVA) was detected in vitro and by the yeast two-hybrid system (YTHS), but it has not been studied in planta.

More recent studies have shown that Arabidopsis thaliana (family Brassicaceae) and tobacco (Nicotiana tabacum; family Solanaceae) encode HIP2 homologs (Shoji et al. 2004). In Arabidopsis, the HIP2 homologs SPIRAL2/TORTIFOLIA1 
(SPR2/TOR1) and SP2L (SPIRAL2-like) were found to originate from an evolutionarily recent genome duplication. They are MT-associated proteins as indicated by their ability to bind tubulin and associate with MT (Buschmann et al. 2004; Shoji et al. 2004; Yao et al. 2008). SPR2 is important for the uninterrupted dynamics and polymerization-driven growth of cortical MT (Yao et al. 2008). Both SPR2 and SP2L are expressed constitutively at low levels in the whole plant and are required by MT for the proper direction of cell elongation. The spr2 lossof-function mutants of Arabidopsis show a conspicuous helical growth phenotype of leaves and petioles, which can be complemented by SP2L (Yao et al. 2008).

There are few studies on the association of plant virus proteins with MT, and virtually nothing is known about interactions of potyviruses with MT or MT-associated proteins such as HIP2 in planta. Therefore, the aim of this study was to investigate HIP2-HCpro interaction and its association with MT to determine if the interactions are essential for potyvirus infection. The data indicate that HIP2-HCpro interactions occur in conjunction with the cortical MT array and that MT- and HCpro-interactions are determined by the $\mathrm{N}$ - and C-proximal regions of HIP2, respectively. Importantly, HIP2 was found to be needed for efficient PVA accumulation in infected plant tissues.

\section{RESULTS}

\section{Potato HIP2 complements}

the SPR2 knock-out phenotype in Arabidopsis.

Phylogenetic comparison of potato HIP2 (StHIP2) with the six Arabidopsis SPR2 family members showed that StHIP2 is closely related to SPR2 and SP2L (Fig. 1A). Tobacco HIP2 (NtHIP2) was characterized (Supplementary Fig. 1) and was found to be 88.7 and $89.1 \%$ identical to StHIP2 at the nucleotide and amino acid levels, respectively.

Arabidopsis plants were grown from seeds of the spr2 knockout mutant SALK_024539 (Nottingham Arabidopsis Stock Centre [NASC], U.K.). The plants exhibiting right-handed helical leaf growth (Fig. 1B) were transformed with StHIP2 placed under the Arabidopsis SPR2 regulatory sequences and were expressed either with the SPR2 3' untranslated region or with monomeric red fluorescent protein (mRFP) fused to the C-terminus (Supplementary Fig. 2A). The StHIP2-transgenic plants expressed StHIP2 and were phenotypically normal, as tested in two subsequent generations (Fig. 1C), regardless of which of the two constructs was used for transformation. Taken together, these results showed that StHIP2 is closely related and functionally similar to SPR2.

\section{Potato and tobacco HIP2 localize at cortical MT.}

Transgenic plants of $N$. benthamiana in which MT were labeled with green fluorescent protein (TUA6-GFP) (Gillespie et al. 2002) were used for subcellular localization of mRFPlabeled StHIP2 and NtHIP2 expressed in the leaves by agroinfiltration. The signal pattern for mRFP-StHIP2 (Fig. 2A) and mRFP-NtHIP2 (Supplementary Fig. 3B) was similar to the cortical MT located under the plasma membrane in interphase cells (Ehrhardt 2008) and in accordance with localization of SPR2 in Arabidopsis (Buschmann et al. 2004; Shoji et al. 2004).

\section{Silencing HIP2}

\section{in $N$. benthamiana reduces virus accumulation.}

$N$. benthamiana HIP2 was silenced by virus-induced gene silencing, using a Tobacco rattle virus (TRV)-derived vector (Ratcliff et al. 2001) carrying a 0.6-kb fragment of NtHIP2 (pTV:hip2). It is $98 \%$ identical to the two HIP2 homologs of $N$. benthamiana, whereas the other six HIP2/SPR2-like genes of $N$. benthamiana are $<50 \%$ identical to NtHIP2 (Sol Genomics Network database; Supplementary Table 1). Lower leaves of small $N$. benthamiana plants were inoculated with pTV:hip2 by agroinfiltration, and HIP2 silencing was manifested as helical growth of the upper systemically infected leaves at 2 to 3 weeks postinfiltration (Fig. 3B). The 'empty' TRV vector (pTV:00) caused no discernible virus symptoms or other changes in plant phenotype (Fig. 3A). Subsequently, the fullgrown or almost full-grown leaves exhibiting an obvious helical growth phenotype in the HIP2-silenced plants were inoculated with an infectious clone of PVA (PVA-GFP) engineered to express GFP from the NIb/CP junction. In three independent experiments, systemic infection with PVA-GFP, green fluorescence appeared in the upper systemically infected leaves of the HIP2-silenced plants slightly later than in the control plants coinfected with 'empty' TRV vector pTV:00 and PVA-GFP, as indicated by a difference in the portion of infected GFP-expressing tissue in the first systemically infected leaves. In HIP2-silenced plants (Fig. 3D), a larger part of the leaf tip remained uninfected than in control plants (Fig. 3C), which is explained by later arrival of PVA in these leaves and the sink-source transition that proceeds from the tip (oldest part) towards the basal part of the leaf and prevents transport and unloading of the virus to the source tissue (Vuorinen et al. 2011).

A slight delay in systemic infection of PVA-GFP in the HIP2-silenced plants could result from slower accumulation or cell-to-cell movement of the virus in the inoculated leaves. To distinguish between these possibilities, PVA-GFP was introduced into leaves by agroinoculation to achieve synchronized infection of most, if not all, cells and, hence, eliminate any significant impact of viral cell-to-cell movement during virus accumulation in infiltrated tissues. Infiltrated leaf areas in the HIP2-silenced leaves (helical growth) exhibited less apparent GFP fluorescence than the control leaves (Fig. 3E). PVA titers

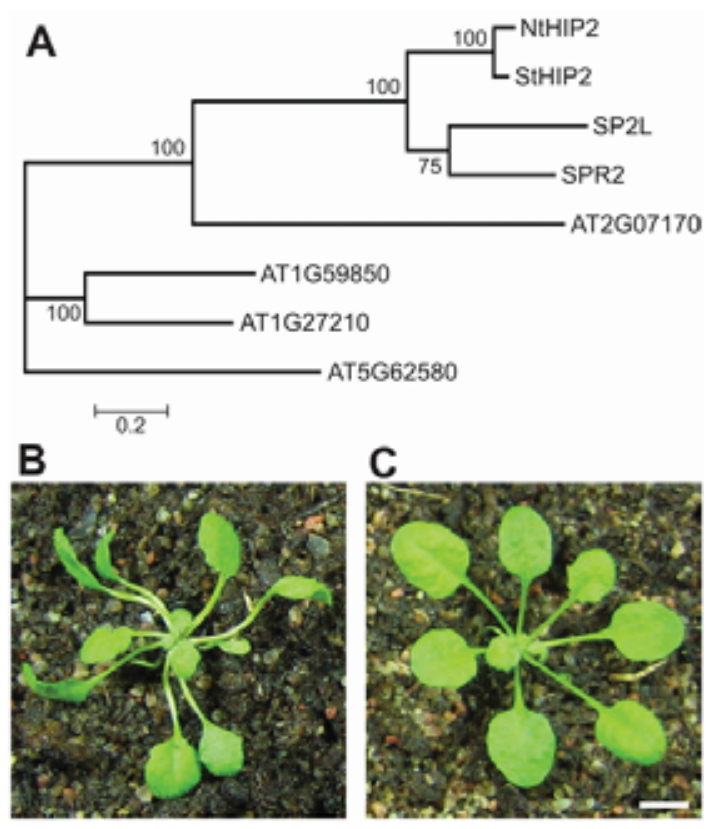

Fig. 1. StHIP2 complements the helical growth phenotype of the Arabidopsis spr 2 knockout mutant. A, Phylogenetic comparison of the deduced amino acid sequences of StHIP2 (potato) and NtHIP2 (tobacco) with six SPR2 family members in Arabidopsis thaliana. SPR2, AT4G27060; SP2L, AT1G50890. The node support values (\%) obtained by bootstrap analysis are indicated at nodes. B, Spiral growth phenotype of the Arabidopsis spr2 knockout mutant. C, spr2 was complemented by genetic transformation for expression of StHIP2, which resulted in normal growth of the plants (plant age, 3 weeks). Scale bar $=0.5 \mathrm{~cm}$. 
determined in the leaf discs excised from the infiltrated area at 3 days postinoculation showed 20 to $60 \%$ reduction in the HIP2-silenced leaves (pTV:hip2) as compared with the TRVinfected control leaves (pTV:00) (Fig. 3F; $P=0.013, t=2.997$, $d f=22$ ). TRV RNA1 and RNA2 were readily detected by reverse transcription-polymerase chain reaction (RT-PCR) in these samples. Quantitive RT-PCR (Q-PCR) analysis showed that the amounts of HIP2 mRNA in the plants infected with pTV:hip2 were only approximately $20 \%$ of those detected in the control plants infected with pTV:00 (Fig. 3F). These results showed that reduced HIP2 expression negatively impacted PVA accumulation in infected cells. PVA accumulation was also lower in the systemically infected HIP2-silenced plants than control plants (Supplementary Table 2).

\section{Subcellular localization}

of HIP2-HCpro interactions in virus-infected cells.

Infection with an engineered clone of PVA (PVA-ynHC; Fig. 4A) expressing HCpro tagged with yellow fluorescence protein (YFP) N-proximal region (YN) and coexpression of NtHIP2 tagged with YFP C-proximal region (YC) in the same tissues of $N$. benthamiana leaves was achieved by introducing the corresponding binary vectors into the leaves by agroinfiltration. HCpro-HIP2 interaction was observed based on reconstitution of YFP, i.e., bimolecular fluorescence complementa- tion (BiFC) (Zamyatnin et al. 2006), along filaments at the cell cortex and also in punctate bodies close to the chloroplasts 4 days postinfiltration (Fig. 4B). In contrast, without coexpression of NtHIP2-YC, subcellular distribution of HCpro was diffuse and cytoplasmic, which was observed in experiments in which HCpro was detected by BiFC based on HCpro selfinteraction. These results can be explained by the reported low levels of endogenous expression of HIP2 (Shoji et al. 2004) and the low proportion of HCpro that could associate with HIP2. Hence, the more specifically localized signals are masked by the majority of HCpro distributed in cytoplasm. This might also be the reason why localization of HCpro on MT has not been noticed in previous studies.

Tubulin fused with mCherry (TUA5-mCherry) (Gutierrez et al. 2009) was expressed in leaves by agroinfiltration together with PVA-ynHC and NtHIP2-YC. BiFC detected interaction between HCpro and NtHIP2, which colocalized with tubulin (Fig. 4C), indicating association with MT (Supplementary Fig. 4). At 3 days postinfiltration, the HIP2-HCpro interaction was predominantly observed at intersections of MT (Fig. 4C), whereas, one day later, localization was apparent also on filaments (Fig. 4B). Indeed, previous studies also show that overexpression of MT-associated proteins for a sufficient time in plant tissues is needed for localization and detection of their interaction partners on MT (Drevensek et al. 2012).
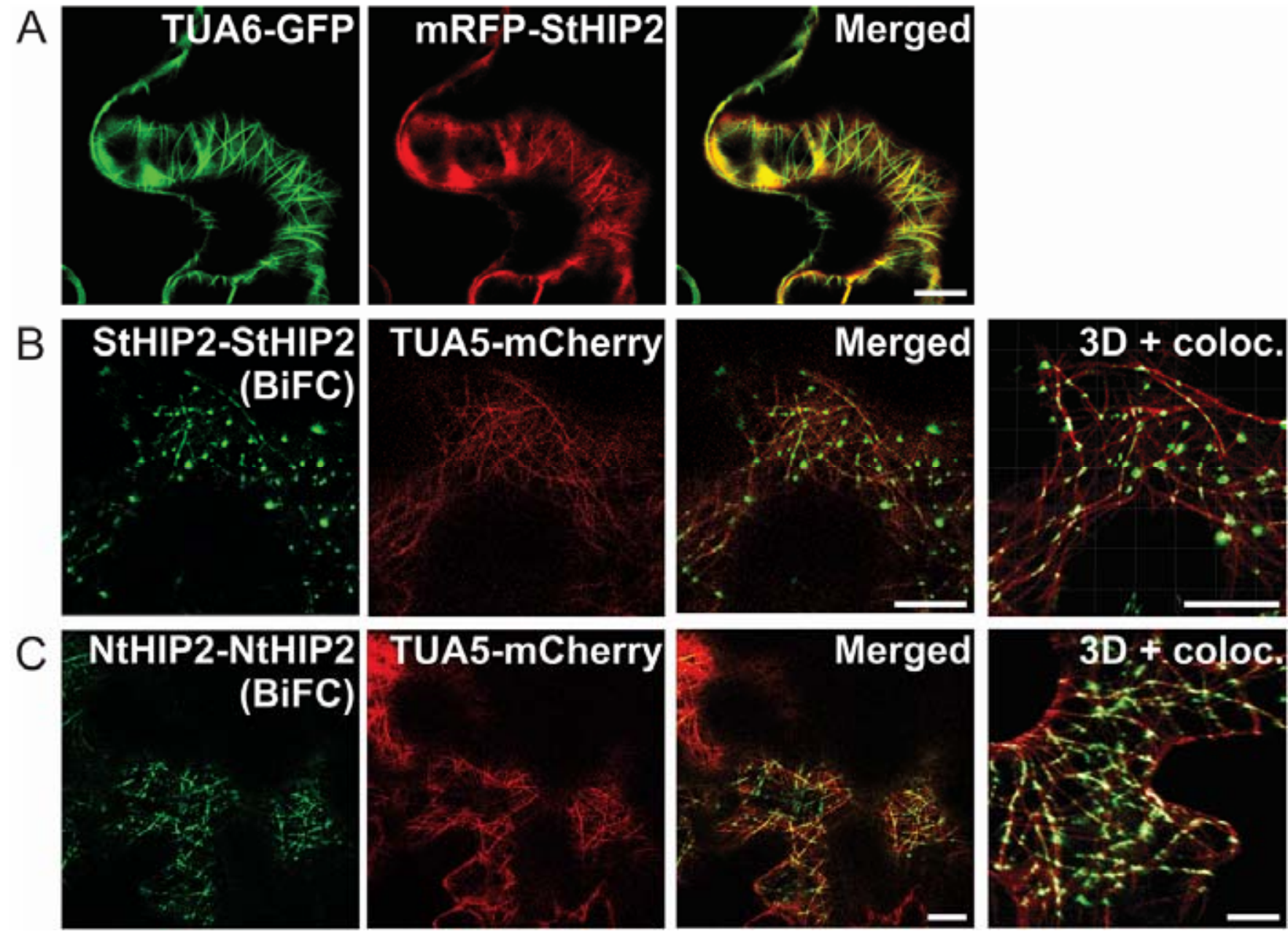

Fig. 2. Subcellular localization of HIP2 on the cortical microtubules (MT) cytoskeleton. A, StHIP2 (tagged with the red fluorescent protein, mRFP) was expressed by agro-infiltration in the leaves of transgenic $N$. benthamiana that expressed tubulin tagged with green fluorescent protein (TUA6-GFP). Confocal microscopy was used to detect mRFP-StHIP2 at the outer cortical plane in the epidermal cells. B, Self-interaction of StHIP2 and C, NtHIP2 detected by bimolecular fluorescence complementation (BiFC) assay and its colocalization with MT that were labeled with TUA5-mCherry. The rightmost figures are deconvoluted 3D images projected to 2D for visualization showing the signal (white color) from the created colocalization channel. The confocal optical sections were captured 2 days postagroinfiltration. Scale bars $=10 \mu \mathrm{m}$. 
To localize the 6K2-induced viral replication vesicles in infected cells, a novel, unique viral vector was developed and used. PVA-ynHC was modified to express also the $6 \mathrm{~K} 2$ protein of PVA fused with mRFP from the NIb/CP junction of the same viral genome (PVA-ynHC/6K2rfp; M. Ala-Poikela, unpublished) (Fig. 4A). PVA-ynHC/6K2rfp was inoculated into $N$. benthamiana by agroinfiltration and accumulated in systemically infected leaves at high titers $(0.3$ to $0.8 \mu \mathrm{g}$ PVA coat protein per gram of fresh weight of leaf tissue), similar to PVA-ynHC (Ala-Poikela et al. 2011) at 9 to 21 days post- inoculation. The YN and 6K2-mRFP inserts in PVA-ynHC/ 6K2rfp were stable in systemically infected leaves, as verified by immunocapture RT-PCR and sequencing of amplicons. Consistent with previous studies on potyviruses (Cotton et al. 2009; Wei et al. 2010a), 6K2-mRFP was observed in the infected cells in vesicles in the cytoplasm or associated with chloroplasts (Fig. 4D and E). The HIP2-HCpro interaction detected by BiFC occasionally colocalized with the PVA replication vesicles detected, based on mRFP fluorescence close to the intersections or branches of MT in the cortical cell layer (Fig. 4D), which has
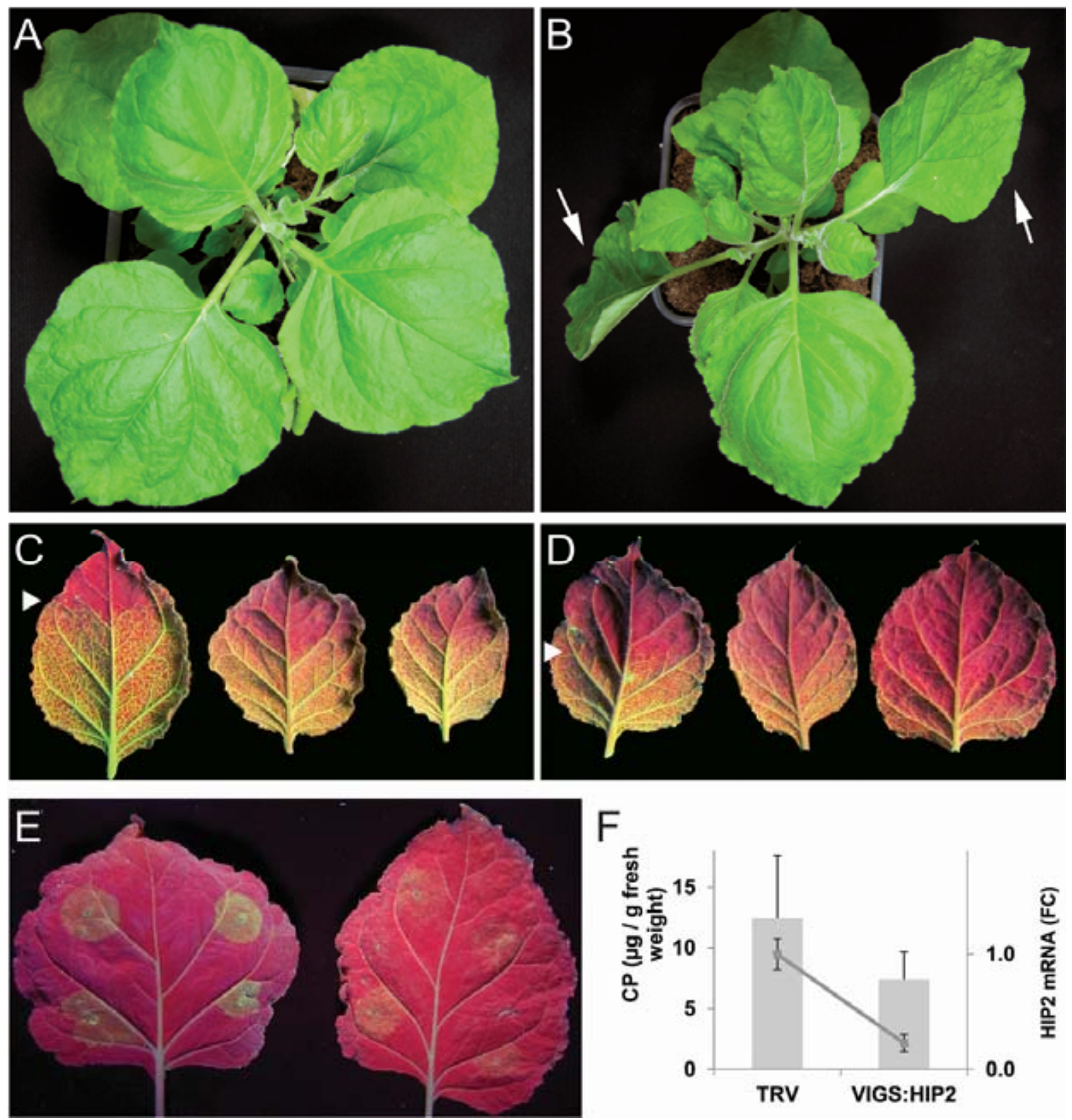

Fig. 3. Silencing of HIP2 in Nicotiana benthamiana and influence on Potato virus A (PVA) infection. A, N. benthamiana systemically infected with the Tobacco rattle virus (TRV)-based gene silencing vector (pTV:00) showed a normal phenotype and no virus symptoms. B, Systemic infection of $N$. benthamiana with pTV:hip2, which carried a 0.6-kb fragment from NtHIP2, induced a helical growth phenotype (arrows) of plants 2 to 3 weeks after TRV inoculation, indicating HIP2 silencing. C and D, Systemic movement of GFP-tagged Potato virus A (PVA-GFP) was slightly slower in plants infected with pTV:hip2 (D) compared with pTV:00 (C), as indicated by the infection frontier closer to the leaf tip in the lowest systemically infected leaves in the pTV:00infected plants (arrowheads). Leaves were photographed under UV light 6 days postinoculation of PVA-GFP. E, Four leaf spots per leaf were inoculated with PVA-GFP by agroinfiltration in the control leaf (left) that was infected with pTV:00 and a leaf that was infected with pTV:hip2 to silence HIP2 (right) prior to PVA-GFP (photos taken 3 days postinoculation with PVA-GFP). F, PVA titers (gray bars) were significantly lower in leaf tissue silenced for HIP2 (VIGS:HIP2) than control leaves (TRV). PVA coat protein (CP) was detected and concentrations estimated in the inoculated tissue by double-antibody sandwich-enzyme-linked immunosorbent assay. Expression levels of HIP2 mRNA were analyzed in the same samples by quantitative reverse transcription-polymerase chain reaction and the difference between the control plants (expression level $=1$ ) and HIP2-silenced plants was expressed as a fold change (FC). Error bars indicate standard deviation. 
not been reported previously. Taken together, these results suggested that HIP2-HCpro interaction did not occur in viral replication vesicles, suggesting that it was not directly involved in viral replication, but was occasionally observed in close proximity to the replication vesicles, implicating a possible role at virus accumulation.

\section{HIP2 self-interacts and localizes to MT.}

Dimerization or multimerization of SPR2 and SP2L has been suggested based on the punctate bodies formed by both proteins on MT (Yao et al. 2008). In our study, BiFC showed that HIP2 self-interacts (Fig. 2B; Supplementary Fig. 5). Similar results were obtained with StHIP2 and NtHIP2, when HIP2
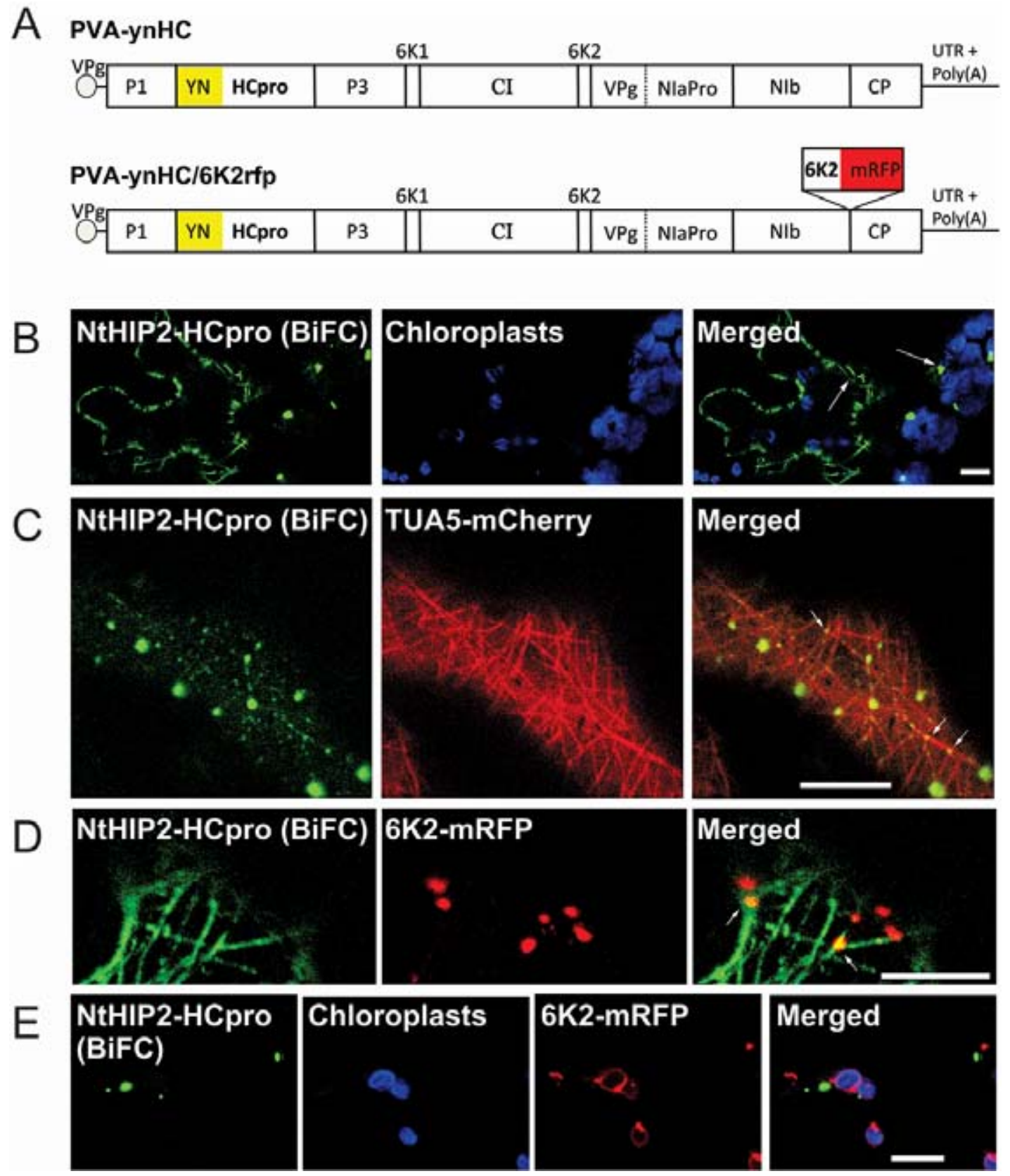

Fig. 4. Localization of HIP2-helper-component proteinase (HCpro) interaction in Nicotiana benthamiana cells infected with Potato virus A (PVA). A, The engineered infectious clones of PVA used expressed the yellow fluorescent protein (YFP) N-proximal (YN) fragment fused to HCpro. Vector PVAynHC/6K2rfp was used to express also PVA 6K2 fused with monomeric red fluorescent protein (mRFP). The 6K2-mRFP fusion was separated from the viral polyprotein by proteolytic cleavage at the flanking NIaPro-specific target sites. The open bar represents the viral polyprotein and vertical lines indicate proteolytic cleavage sites. The mature viral proteins are P1, first protein; HCpro, helper component proteinase; $\mathrm{P} 3$, third protein; 6K1 and 6K2, 6-kDa proteins; $\mathrm{CI}$, cylindrical inclusion protein; VPg, viral genome-linked protein, covalently attached to the $5^{\prime}$ end of the viral RNA; NIaPro, the main viral proteinase; NIb, replicase; CP, coat protein. The $5^{\prime}$ and $3^{\prime}$ ends of the viral genome contained untranslated regions (UTR), and the $3^{\prime}$ end contained a poly(A) tail. B, Interaction between NtHIP2 and HCpro was detected by bimolecular fluorescence complementation (BiFC) (arrows in the merged image) along the cortical filaments and in large punctate bodies in proximity of chloroplasts showing blue autofluorescence in leaf tissue coexpressing PVA-ynHC and NtHIP-YC at 4 days postagroinfiltration. YN-HCpro was expressed from PVA-ynHC in the course of virus infection, whereas NtHIP2-YC was coexpressed from a binary vector. C, Coexpression of tubulin (tagged with TUA5-mCherry) and NtHIP2-YC by agroinfiltration in tissues infected with PVA-ynHC at 3 days postinfiltration. The interacting HCpro-HIP2 colocalized with microtubules (MT) and intersections of MT. D and E, Viral replication vesicles (6K2-mRFP) were detected at the cortical MT array at 3 days postinfiltration. MT were labeled with BiFC signals generated by HCpro-HIP2 interaction. Replication vesicles were associated with chloroplasts (E), crosses of MT (arrows) (D), and occasionally, with punctate bodies and the labeled MT-array (BiFC signals). The confocal images are single optical sections in B and $\mathrm{E}$ and overlays of two consecutive sections in $\mathrm{C}$ and $\mathrm{D}$. Scale bars $=10 \mu \mathrm{m}$. 
was tagged at its $\mathrm{N}$ - or C-terminus with YN or YC. HIP2 selfinteractions were localized by coexpressing mCherry-labeled tubulin in the same cells by agroinfiltration. Signals of HIP2 self-interaction were observed along the cortical MT at the cell periphery and in punctate bodies at the MT crossing points (Fig. 2B). Deconvolution and colocalization analysis of the confocal images provided enhanced resolution to colocalization of HIP2 and MT (Fig. 2B and 2C, rightmost images; Supplementary Fig. 6; Supplementary Movie 1). The localization pattern was similar to the mRFP-tagged StHIP2 and NtHIP2 and dependent on intact MT, as confirmed by depolymerization of MT using colchicine treatment, followed by inspection of the epidermal cells using an epifluorescence microscope (Supplementary Fig. 7).

\section{Predicting HIP2 structure.}

Secondary structures of HIP2 were predicted and analyzed in silico with several algorithms (discussed below). Results indicated that StHIP2 (862 residues) is a predominantly $\alpha$ helical protein that contains a basic serine-rich region (40 residues) and HEAT repeats at the N-terminus, as reported for SPR2 (Shoji et al. 2004). The six putative HEAT repeats were validated using the HHpred and Coach algorithms (Fig. 5A). The HEAT repeat region showed significant homology with
A
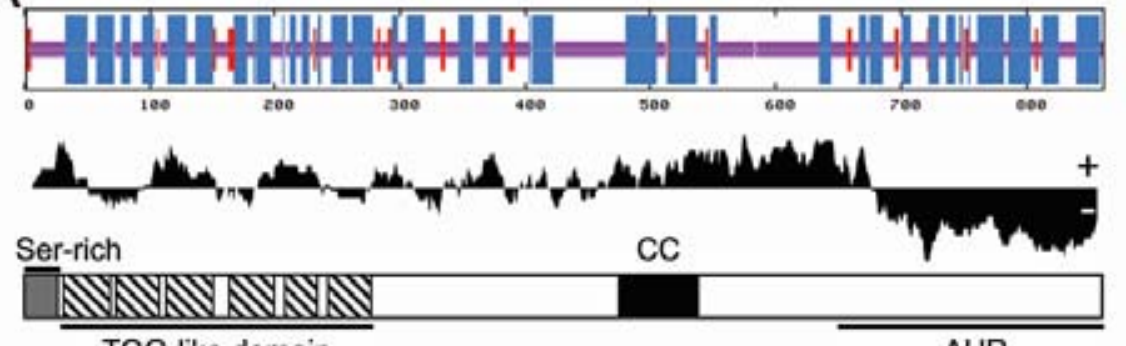

TOG-like domain

B

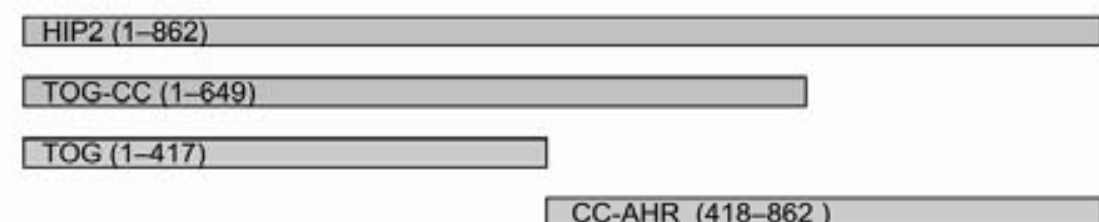

CC-AHR (418-862)

AHR (650-862)
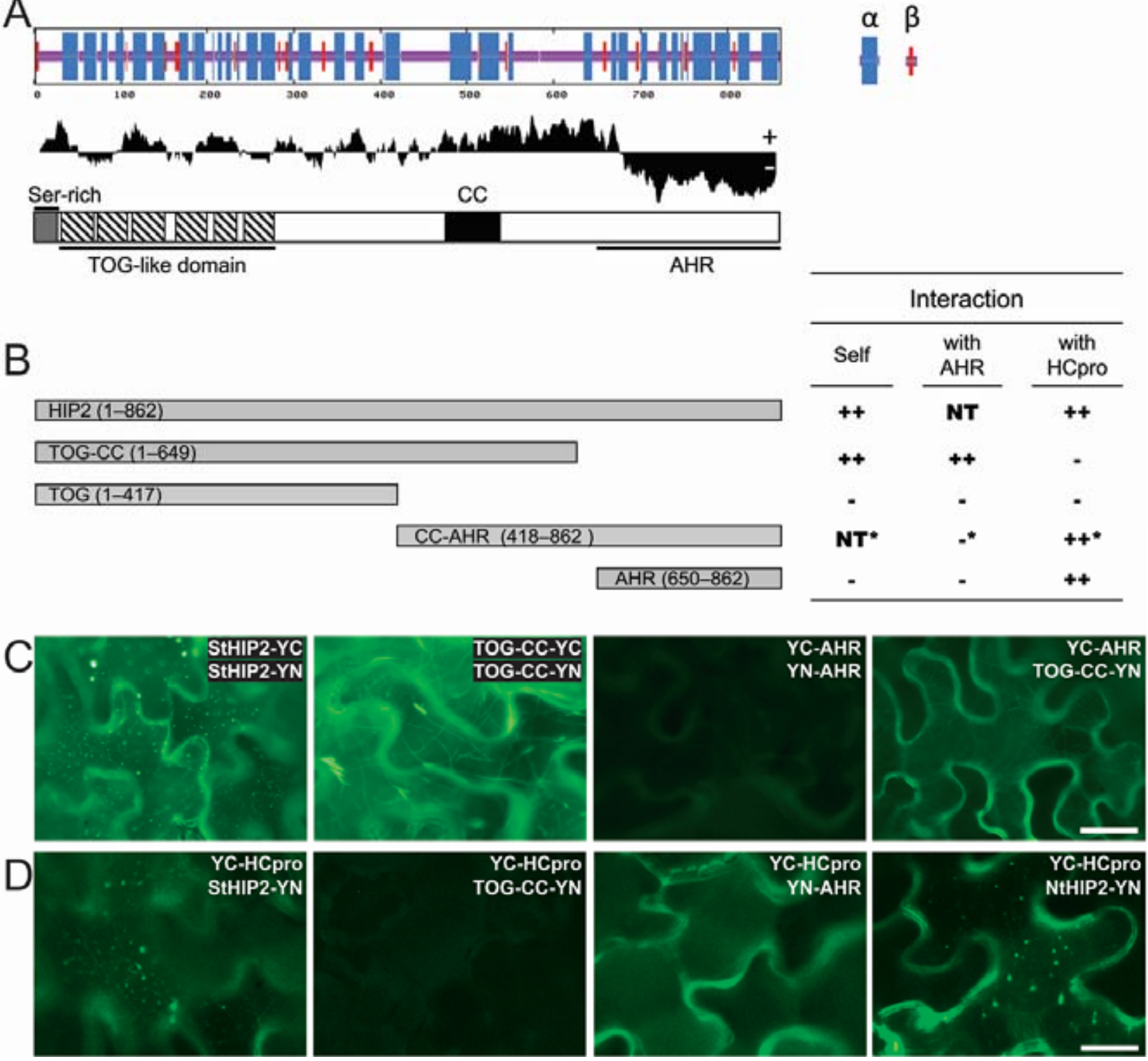

Fig. 5. Structural predictions for HIP2 and the domains involved in HIP2 self-interaction and interaction with helper-component proteinase (HCpro). A, Secondary structures and structural domains of StHIP2 (862 residues) predicted with NPS@. The putative $\alpha$-helix and $\beta$-strand structures are indicated by blue and red bars, respectively (top). The protein charge blot (middle) indicates the positive (basic) or negative (acidic) charge of the residues above and below the baseline, respectively. The protein domain map (bottom) displays a basic serine-rich region (40 residues), a TOG domain consisting of six HEAT repeats (striped), a coiled-coil (CC) domain, and an acidic $\alpha$-helix-rich (AHR) region, respectively. B, Interactions of the full-length and truncated StHIP2 proteins with themselves (Self), with AHR (residues 650 to 862), or with Potato virus A (PVA) HCpro; ++ = strong interaction indicated by efficient growth of yeast; $-=$ no yeast growth indicating no detectable interaction. $\mathrm{nt}=$ not tested; an asterisk $\left({ }^{*}\right)$ indicates interactions of CC-AHR were tested only as an activationdomain fusion protein, because this protein autoactivated reporter gene transcription when expressed as a binding-domain fusion protein. All other proteins were tested as activation-domain and binding-domain fusion proteins. $\mathbf{C}$ and $\mathbf{D}$, In planta interactions of StHIP2 and the truncated forms, as tested by bimolecular fluorescence complementation in Nicotiana benthamiana and observed with epifluorescence microscopy. Additionally, interaction of NtHIP2 with PVA HCpro is shown (D). YN and YC refer to the $\mathrm{N}$ - and C-proximal halves of the yellow fluorescent protein (YFP), respectively. Images in C and D were captured 3 days postagroinfiltration. Scale bars $=20 \mu \mathrm{m}$. 
the TOG-like (tumor overexpressed gene protein) (Charrasse et al. 1995) domains (e.g., PF12348) according to an HHpred search in the PfamA database, which was not noted in previous studies on SPR2. The TOG domain is common in MT (+)-end associated proteins, and is involved in recruitment and polymerization of free tubulin heterodimers (Slep and Vale 2007). Furthermore, HHpred searches in the Protein Data Bank (pdb) revealed strong similarities (probability $>99.5$; Evalues $<5 \mathrm{e}-14$ ) between the HEAT repeat region of StHIP2 and the resolved structures of TOG domains in the MAP215 family proteins of Drosophila melanogaster (MSPS, pdb id: 2QK2) and Caenorhabditis elegans (ZYG-9, pdb id: 2OF3). Therefore, the HEAT repeat region was putatively designated as a TOG domain and is so referred to in this study. The two $\alpha$-helices in the central part of StHIP2 were recognized as a putative coiled-coil (CC) domain by the COILS algorithm and were flanked by disordered regions, as predicted by DisProt VSL2B. The C-proximal $\alpha$-helix-rich region (AHR; approximately 200 residues) of StHIP2 (Fig. 5A), NtHIP2, SPR2, and SP2L was acidic in its amino acid composition.

\section{Two domains of HIP2 control molecular self-interactions.}

Self-interactions of StHIP2, NtHIP2, and also SPR2 were further confirmed by YTHS. Truncated forms of StHIP2 were designed according to the structural model to map protein regions contributing to HIP2 self-interaction (Fig. 5B, Supplementary Fig. 8). Expression of the proteins in planta and in yeast was verified by Western blotting. Taken together, the results indicated that StHIP2 contained two regions participating in intra- or intermolecular self-interactions. The TOG-CC domain at the $\mathrm{N}$-proximal region was able to self-interact, whereas no self-interaction was observed with AHR located at the C-proximal region of StHIP2 (Fig. 5B). Additionally, the TOG-CC and AHR domains interacted with each other. The aforementioned interactions were also tested in vivo, using $\mathrm{BiFC}$, and results were consistent with those obtained with YTHS (Fig. 5C).

The AHR domain of HIP2 controls interaction with HCpro.

Interaction of NtHIP2 with HCpro of PVA was detected using YTHS, consistent with the reported interaction of StHIP2 with PVA HCpro (Guo et al. 2003), which was reconfirmed. Experiments with the truncated forms of StHIP2 revealed no interaction between TOG or TOG-CC and HCpro, whereas interactions between AHR or CC-AHR and HCpro were readily detected using YTHS (Fig. 5B) and BiFC in planta (Fig. 5D). HCpro-AHR interaction was cytoplasmic and evenly distributed in cells (Fig. 5D), whereas the StHIP2-HCpro and NtHIP2-HCpro interactions were detected at the cell periphery along MT and in punctate bodies (Figs. 4B, C, and D). Taken together, these results suggested that the AHR region of HIP2 determined the interaction between HIP2 and HCpro, whereas the TOG-CC region-responsible for HIP2 self-interaction and association with MT-localized the HIP2-HCpro interaction to the MT cytoskeleton.

\section{DISCUSSION}

Our results provide the first example of in vivo interactions of potyviral proteins with MT-associated proteins and association with the MT cytoskeleton in planta and extend our initial observation of HIP2-HCpro interactions in yeast cells and in vitro (Guo et al. 2003). Results showed that HIP2 proteins characterized from $S$. tuberosum and N. tabacum (family Solanaceae) are MT-associated proteins aligned along the cortical MT. They are phylogenetically related to the MT (+)-end protein SPR2 of A. thaliana (family Brassicaceae) (Buschmann et al. 2004; Shoji et al. 2004) and also functionally homologous, as shown by complementation of the right-handed helical (spiral) growth spr2 knockout phenotype in Arabidopsis with StHIP2. Furthermore, silencing HIP2 in N. benthamiana resulted in helical growth resembling the spr2 knockout phenotype. Results also show that the C-proximal AHR domain of HIP2 controls heterologous interactions with HCpro at the cortical MT array in PVA-infected cells, whereas the TOG-CC domain is needed for localization of HIP2 to the MT array.

Depletion of HIP2 in $N$. benthamiana to the extent sufficient to induce the spiral growth phenotype reduced PVA accumulation in the inoculated tissues, which caused a delay in systemic infection with PVA. These results are significant, because only few studies have suggested that interactions with MT-associated proteins are important in plant virus infections and no reports are available from members of family Potyviridae, the largest family of plant-infecting RNA viruses. Tobacco mosaic virus (TMV, family Virgaviridae) movement protein (MP) interacts with the MT (+)-end component EB1 and with MP2BC, which colocalizes with MT and stabilizes them. Overexpression of EB1 reduces cell-to-cell movement of TMV $\mathrm{MP}$, whereas MP2BC is required for accumulation of MP on MT (Brandner et al. 2008; Ruggenthaler et al. 2009). MP2BC is also an RNA-binding protein that interacts with a secondary structural element in the genomic RNA of Potato virus $X$ (PVX, family Alphaflexiviridae) and with three movementassociated proteins of PVX (Cho et al. 2012). During PVX infection, MP2BC is relocated from MT to the ER and plasmodesmata, which interferes with viral movement (Cho et al. 2012). The p 25 protein of Beet necrotic yellow vein virus (family Virgaviridae) interacts with a HIP2 homolog in sugar beet (Beta vulgaris) (Thiel and Varrelmann 2009), and MP (sc4) of Sonchus yellow net virus (Rhabdoviridae) interacts with a putative kinesin MT motor protein at cortical MT in planta (Min et al. 2010), but the significance of these interactions remains to be determined.

HIP2-HCpro interactions were pronounced at the intersections of MT. This localization pattern of HIP2-HCpro interaction is compatible with the known roles of the cytoskeleton in cellular physiology and plant virus infection. In potyvirus infection, intact actin filaments are essential because replication vesicles induced by the viral $6 \mathrm{~K} 2$ protein are targeted to chloroplasts by COPII- and actin-dependent transport pathways (Cotton et al. 2009; Wei et al. 2010a). Subsequently, the chloroplasts move closer to each other along actin filaments, possibly to provide a protected and energy-rich environment for virus replication and assembly, and they are anchored to the MT cytoskeleton (Chuong et al. 2006; Takagi et al. 2009; Wei et al. 2010a). Results on localization of HIP2 and the HIP2-HCpro interaction were consistent and suggest that HIP2 is concentrated at the intersections of MT, which also induces HCpro concentration at the crossings. Various proteins that bind to cytoskeletal elements, including some MT (+)-end proteins (Petrášek and Schwarzerová 2009), may mediate actin-MT interactions and also associate with the plasma membrane or endomembranes (Deeks et al. 2010; Dryková et al. 2003; Mathur et al. 2003). Cell organelles, P-bodies, and secretory vesicles that are transported on actin regularly pause at MT, implicating these cortical sites in putative cargo recycling or cargo exchange and secretion (Chuong et al. 2006; Crowell et al. 2009; Hamada et al. 2012; McFarlane et al. 2008). For viruses, these sites could be favorable for recruitment of various host factors or for regulation of cellular signaling.

Localization of HIP2-HCpro interactions was clearly different from the colocalization of potyviral proteins and the host components required for virus replication (Beauchemin et al. 2007; Cotton et al. 2009; Dufresne et al. 2008; Huang et al. 2010; 
Thivierge et al. 2008; Wei et al. 2010a), including HCproeIF(iso)4E interactions that colocalize regularly with the $6 \mathrm{~K} 2-$ induced viral replication vesicles (Ala-Poikela et al. 2011). Our results were obtained using a novel and relevant approach that allowed coexpressing YN-HCpro (to localize HCpro-HIP2 interaction) and 6K2-mRFP (to localize viral replication vesicles) from the same replicating viral genome in infected cells rather than expressing one or both tagged viral proteins from transient expression vectors introduced by agroinfiltration, as in previous studies. Hence, protein localizations mimicked the natural situation in the infection context as closely as possible. Therefore, our results suggest that HIP2-HCpro interaction is not directly involved in viral replication. However, it might participate in controlling host responses and, hence, modulate cellular environment for the benefit of virus accumulation.

Potyviral HCpro alters expression of various transcription factors and signaling pathways controlling development and pathogen defense in plants (Pacheco et al. 2012; Soitamo et al. 2011). The role of MT in plant defense-signal amplification is also becoming apparent (Qiao et al. 2010; Shi et al. 2009; Yao et al. 2011). Data available from an interaction screen of Arabidopsis proteins to elucidate immune system networks (Salk Institute Genomic Analysis Laboratory database; Mukhtar et al. 2011) shows that SPR2 interacts with many receptor-like kinases and with two transcription factors related to immune responses and morphogenesis. Receptor-like kinases are membrane proteins functioning as sensors in various responses to developmental or external cues (Afzal et al. 2008; De Smet et al. 2009), and interactions with them suggest that SPR2 (HIP2) may integrate signaling networks involved in defense responses. These recent findings require further elucidation, but they suggest that HCpro may interact with HIP2 to interfere with host signaling for antiviral defense.

Subcellular localization of HIP2 and SPR2 (Yao et al. 2008) in punctate bodies on the cortical MT array suggests that the proteins may form dimers or multimers. Indeed, our results showed that SPR2, StHIP2, and NtHIP2 self-interact, and BiFC revealed the self-interacting StHIP2 and NtHIP2 in the cortical MT array as filaments and punctate bodies. Structural predictions revealed a TOG-like domain with six HEAT repeats in the N-proximal region of HIP2 and, consistent with the previous findings on SPR2 (Yao et al. 2008), the putative TOG domain was involved in localization of HIP2 to the MT cytoskeleton. Hence, dimerization and MT association of HIP2 might be functionally linked, as in the yeast, in which the TOG domain protein Stu2 regulates MT dynamics (Al-Bassam and Chang 2011). Affinity to MT can be regulated by positively charged areas, as in TRM1 (Drevensek et al. 2012), or by positively charged loops between the $\alpha$-helices in the TOG domain, as in MOR1, a MAP215-homolog of Arabidopsis (Lechner et al. 2012). The C-proximal domain of HIP2, including an acidic AHR region, was able to interact with the TOG-CC domain but was not able to dimerize like the TOG-CC domain. Hence, AHR may contribute to HIP2 multimerization, which, in turn, may increase affinity of HIP2 for MT and offer HIP2 a mechanism for regulating MT binding and dissociation. This hypothesis is bolstered by studies showing that the number of TOG domains in the MAP215 family correlates positively with the affinity of these proteins for MT (Al-Bassam and Chang 2011). It suggests that HIP2 shares similar features with proteins of the conserved MAP215 and CLASP families of MT-associated proteins containing serine-rich regions and TOG domains, which are also the key organizers of the plant cortical MT array (Al-Bassam and Chang 2011).

Taken together, the results resolved new aspects of functions of the structural domains of the MT-associated protein HIP2, an ortholog of Arabidopsis SPR2/SP2L, and their involvement in intra- and intermolecular self-interactions and heterologous interactions. The results also showed that interactions of HIP2 with potyviral HCpro are significant to potyvirus infection. These results suggest novel possibilities to control potyviral diseases in plants by interfering with interactions between HCpro and MT-associated proteins.

\section{MATERIALS AND METHODS}

\section{Plant material.}

Seeds of the transgenic $N$. benthamiana line GFP-TUA6 (Gillespie et al. 2002) were a gift from K. Oparka, University of Edinburgh, Scotland. Seeds of the A. thaliana T-DNA-insertion spr2 knockout line (SALK_024539; Alonso et al. 2003) and the Landsberg-1 and Columbia- 8 ecotypes were obtained from the Nottingham Arabidopsis Stock Centre. Potato v2lines (Vuorinen et al. 2010) were obtained from our in vitro collection. Plants in growth rooms $(16 \mathrm{~h}$ photoperiod at 18 and $22^{\circ} \mathrm{C}, 70 \%$ relative humidity, $200 \mu \mathrm{E} \mathrm{m} \mathrm{m}^{-2} \mathrm{~s}^{-1}$ light intensity) were given $0.3 \mathrm{~g}$ of fertilizer per liter(16:9:22 = N/P/K; Yara, Espoo, Finland) at every watering.

\section{Cloning of StHIP2, NtHIP2, and SPR2.}

Total RNA was extracted using homemade Trizol (Caldo et al. 2004). First-strand cDNA synthesis was performed using PowerScript reverse transcriptase (Clontech, Mountain View, CA, U.S.A.) and a polyT+N-primer. Target genes were amplified using Phusion high-fidelity DNA polymerase (Finnzymes, Espoo, Finland). StHIP2 was amplified from the cDNA of potato line $2 x(\mathrm{~V}-2) 7$ (Vuorinen et al. 2010), was verified by sequencing of PCR products (accession number HE653966), and was found to contain five nucleotide and four amino-acid substitutions as compared with the published sequence (AJ507317; Guo et al. 2003). NtHIP2 was amplified from the cDNA of $N$. tabacum cv. Samsun nn using forward and reverse primers designed based on conserved regions in StHIP2/SPR2/SP2L and an expressed sequence tag clone (National Center for Biotechnology Information [NCBI] accession number EB677952). Three clones were sequenced for verification, and the sequence was deposited in the NCBI sequence database (accession number HE649915). SPR2 was amplified from A. thaliana Landsberg-1 (NASC) with primers designed according to an Arabidopsis cDNA sequence (accession number $\mathrm{AB} 176521$ ) and was verified by sequencing. In Nicotiana benthamiana, a species with an allotetraploid origin, eight homologs of HIP2/ $S P R 2 / S P 2 L$ were found in the draft genome (Sol Genomics Network). Two homologs were $98 \%$ identical to NtHIP2, whereas the other six genes were less than $50 \%$ identical.

\section{Multiple sequence alignment and structure prediction.}

Amino acid sequences were aligned with ClustalW (ClustalW2 program). The best-scoring tree was computed with RAxML (RAxML BlackBox database) that uses the WAG replacement model (Whelan and Goldman 2001) as an evolutionary substitution model, combines a rapid bootstrap heuristic (100 replications) to a maximum-likelihood search, calculates node support values, and selects the best-scoring tree (Stamatakis et al. 2008).

HIP2 secondary structures were predicted using several algorithms on the NPS@ server (Combet et al. 2000) or with Jnet (v2.2) (Cole et al. 2008). Putative HEAT repeats were searched with algorithms HHpred (Söding et al. 2005) in the PfamA database and Coach (Edgar and Sjölander 2004) against a template set of HEAT-repeat sequence patterns of Kippert and Gerloff (2009). Coiled-coil regions were analyzed with Coils (Lupas et al. 1991), and the putative disordered flanking regions were predicted with DisProt VSL2B (Peng et al. 2006). 
A protein charge blot was constructed using a sliding window of 51 residues (Drevensek et al. 2012).

\section{Transformation of Arabidopsis.}

DNA was extracted from Arabidopsis leaf tissue (spr2 knock-out line SALK_024539), and plants were screened for homozygosity of the T-DNA-insertion locus with PCR (Alonso et al. 2003). Seeds from homozygous plants were collected and were grown to obtain plants for transformation. Transformation vectors were made using the multisite Gateway technology with standard techniques (Invitrogen, Carlsbad, CA, U.S.A.). The $S P R 2$ promoter (2,035 nt upstream from the $S P R 2$ start codon) and a 3' end fragment of SPR2 (960 nt downstream from the stop codon) were amplified from genomic DNA of $A$. thaliana ecotype Columbia-8 (NASC). The sequence of $m R F P$ (AJ851291) was amplified by PCR from plasmid pLH-6K2-RFP (Ala-Poikela et al. 2011). The resulting vectors were sequenced, and the inserts recombined to the plant-expression cassettes within the transformation vector (Karimi et al. 2005). The binary plasmids were introduced to Agrobacterium tumefaciens $\mathrm{C} 58 \mathrm{C} 1 \mathrm{pGV} 2260$, which was used to transform inflorescences of the Arabidopsis spr2 knockout plants, and the seeds obtained were germinated under phosphinothricin selection (Zhang et al. 2006). Putative transformants were transferred to soil, and the first $\left(\mathrm{T}_{1}\right)$ and second $\left(\mathrm{T}_{2}\right)$ generations resulting from self-pollination were tested for homozygosity of the transgene locus, as above. Total RNA extracted from the transgenic lines was treated with DNase (Promega, Madison, WI, U.S.A.), and the expression of the StHIP2 transgene was confirmed by RT-PCR.

\section{Virus-induced gene silencing.}

A fragment of NtHIP2 cDNA $(0.6 \mathrm{~kb})$ including the AHR domain was amplified by PCR and cloned into the SmaI site of TRV RNA2 vector pTV00 (Ratcliff et al. 2001), and the construct (pTV:hip2) was transformed into Agrobacterium tumefaciens GV3101. Arobacterium tumefaciens strains carrying TRV RNA1 (pBINTRA6) and RNA2 (pTV:00 or pTV-hip2) were combined in a 1:1 ratio ( $\mathrm{vol} / \mathrm{vol})$ and were agroinfiltrated into fully expanded or almost fully expanded leaves of $N$. benthamiana, as described (Rajamäki and Valkonen 2009).

\section{Virus detection, enzyme-linked immunosorbent assay (ELISA), and Q-PCR.}

PVA was detected in plants by double-antibody sandwich (DAS)-ELISA, using a monoclonal antibody against PVA-CP (PVA-58/0) and an alkaline phosphatase-conjugated PVA-58/0 (Science and Advice for Scottish Agriculture, Edinburgh, U.K.), as described (Rajamäki et al. 1998). Leaf samples were weighed, were ground in sample buffer at $0.1 \mathrm{~g} \mathrm{ml}^{-1}$, and were diluted 20- to 100-fold with the sample buffer, and aliquots of $100 \mu \mathrm{l}$ were transferred to wells of microtiter plates coated with PVA antibodies. Known amounts of purified PVA virions were included for comparison to estimate virus concentration. Differences in virus titer in discs taken from the centers of infiltrated areas were statistically analyzed with a $t$-test using the statistical package PASW (v.18.0.3) (IBM, Armonk, NY, U.S.A.).

Total RNA was extracted from leaves using homemade Trizol and treated with DNase, and cDNA was synthesized using Moloney murine leukemia virus reverse transcriptase (Promega). Q-PCR was run using SYBR Green I master mix and LightCycler 480 instrument (Roche, Mannheim, Germany). Foldchange values were calculated as described (Pfaffl 2001).

\section{BiFC and fluorescently labeled proteins.}

The BiFC system was based on the binary vector pLH7000 used to express proteins fused with the $\mathrm{YN}$ or $\mathrm{YC}$ half of the
YFP under Cauliflower mosaic virus 35S promoter, and the expression constructs were introduced into leaf tissue by agroinfiltration, as described (Zamyatnin et al. 2006). BiFC vectors for expression of YN- and YC-tagged PVA HCpro have been described (Ala-Poikela et al. 2011), and the vectors for expression of YN- and YC-tagged NtHIP2, StHIP2, or fragments of StHIP2 were prepared following the same procedures. pLHmRFP-StHIP2 and pLH-mRFP-NtHIP2 were obtained by releasing the $\mathrm{YN}$-encoding fragment from $\mathrm{pLH}-\mathrm{YN}$ by digestion with $X h o I$ and NcoI and amplifying the gene for mRFP (with primers containing XhoI and PciI sites) and the HIP2 encoding sequences (with primers containing NcoI), followed by simultaneous ligation. All constructs were verified by sequencing.

The infectious clone PVA-ynHC inserted in the binary vector pCAMBIA0390 (Ala-Poikela et al. 2011) was modified by amplifying the 6K2-mRFP sequence from pLH-6K2-mRFP (Ala-Poikela et al. 2011) and inserting the sequence for 6K2mRFP into the NIb/CP junction (Kelloniemi et al. 2006). The new infectious clone was designated as PVA-ynHC/6K2rfp. Infectivity was tested in $N$. benthamiana inoculated by particle bombardment or agroinfiltration (Rajamäki and Valkonen 2009).

In BiFC, MT cytoskeleton was visualized with transiently expressed Arabidopsis tubulin $\alpha-5$ fused with mCherry (TUA5mCherry; Gutierrez et al. 2009). MT cytoskeleton was disrupted in leaves of $N$. benthamiana by treatment with colchicine to depolymerize MT, essentially as described (Gillespie et al. 2002).

\section{Fluorescence and confocal microscopy.}

BiFC signals were visualized with a Leitz Laborlux S microscope with an epifluorescence extension Leitz Ploemopak (Leica Microsystems GmbH, Wetzlar, Germany). Epidermal cells on the abaxial side of the agroinfiltrated leaves were viewed at 2, 3, and 4 days postinfiltration, using a YFP-compatible filter cube $(470 / 40 \mathrm{~nm}$ excitation, $500 \mathrm{~nm}$ dichromatic mirror; 525/50 nm emission; Leica). Images were captured with a CCD-camera (DP-50; Olympus, Tokyo) controlled by ViewLite (v1.0) (Olympus). Confocal microscopy was performed using a SP2 AOBS confocal laser-scanning system mounted on an inverted Leica DM IRE2 microscope (Leica) with a water immersion objective HCX PL APO $(63 \mathrm{x} / 1.2 \mathrm{~W})$ at the Institute of Biotechnology, University of Helsinki. For simultaneous detection of YFP, chloroplasts, and mRFP, specimens were scanned using sequential settings: excitation at 514 $\mathrm{nm}$, emission filters at 520 to $565 \mathrm{~nm}$ (YFP), 680 to $740 \mathrm{~nm}$ (chloroplast autofluorescence), and excitation at $561 \mathrm{~nm}$, emission at 590 to $630 \mathrm{~nm}$ (mRFP). For simultaneous detection of mRFP, GFP, and chloroplasts, excitation was at $488 \mathrm{~nm}$ and emission at 497 to $522 \mathrm{~nm}$ for GFP. Images were processed using Leica Application Suite Advanced Fluorescence Lite and Adobe Photoshop CS5 (Adobe Systems Incorporated, San Jose, CA, U.S.A.). To increase resolution, the acquired optical sections were deconvoluted with AutoQuantX3 (MediaCybernetics, Rockville, MD, U.S.A.), using blind 3D deconvolution algorithm, the refractive index value of 1.33 for immersion, and 1.4 for sample mediums and employing an axial stretch factor of 3. The resulting 3D image was processed with Imaris (v7.4.2) (Bitplane, Zürich, Switzerland) to create a colocalization channel from YFP and RFP channels. Intensity thresholds estimated visually from the histograms were applied to both channels before colocalization was calculated. 2D projections and animations were visualized with the Surpass View tool.

\section{YTHS assay.}

NtHIP2 and SPR2 genes and the deletion mutants of StHIP2 were amplified from the sequenced cDNA clones with Phusion, and the restriction sites needed for cloning were 
added with primers. Cloning into the YTHS vectors pGBKT7 and pGADT7 for expression in fusion with the DNA-binding domain and transcription-activation domain, respectively, the YTHS vectors containing the HCpro encoding sequence of PVA-B11, the yeast strain and their transformation have been described (Ala-Poikela et al. 2011). Synthetic minimal medium lacking leucine and tryptophan was used to select for transformed yeast, and protein-protein interactions were detected by growth on medium lacking adenine, histidine, leucine, and tryptophan at $30^{\circ} \mathrm{C}$ for up to 14 days, as described (Clontech).

\section{ACKNOWLEDGMENTS}

We thank M. Ala-Poikela for constructing PVA-ynHC/6K2rfp, J. Santala, S. Siddiqui, and X. Deng (our laboratory), and Y. Helariutta and S. Lehesranta (Department of Biosciences, University of Helsinki) for materials and advice, D. Ehrhardt (Carnegie Institution for Science, Washington, DC, U.S.A.), K. Oparka (University of Edinburgh, U.K.), and D. Baulcombe (University of Cambridge, U.K.) for materials, and M. Crivaro, M. Molin, and K. Tanhuanpää (Institute of Biotechnology, University of Helsinki) for advice in confocal microscopy and deconvolution analysis. Financial support from the Academy of Finland (grants 111866 1134759, and 1253126 to J. P. T. Valkonen) and the Finnish Doctoral Program in Plant Sciences (to T. Haikonen) is gratefully acknowledged.

\section{LITERATURE CITED}

Adams, M. J., Zerbini, F. M., French, R., Rabenstein, F., Stenger, D. C., and Valkonen, J. P. T. 2012. Family Potyviridae. Pages 1069-1089 in: Virus Taxonomy, Ninth Report of the International Committee on Taxonomy of Viruses, A. M. Q. King, M. J. Adams, E. B. Carstens, and E. J. Lefkowitz, eds. Elsevier Academic Press, London, U.K.

Afzal, A. J., Wood, A. J., and Lightfoot, D. A. 2008. Plant receptor-like serine threonine kinases: Roles in signaling and plant defense. Mol. Plant-Microbe Interact. 21:507-517.

Ala-Poikela, M., Goytia, E., Haikonen, T., Rajamäki, M.-L., and Valkonen, J. P. T. 2011. Helper component proteinase of the genus Potyvirus is an interaction partner of translation initiation factors eIF(iso) $4 \mathrm{E}$ and eIF4E and contains a 4E binding motif. J. Virol. 85:6784-6794.

Al-Bassam, J., and Chang, F. 2011. Regulation of microtubule dynamics by TOG-domain proteins XMAP215/Dis1 and CLASP. Trends Cell Biol. 21:604-614.

Alonso, J. M., Stepanova, A. N., Leisse, T. J., Kim, C. J., Chen, H., Shinn, P., Stevenson, D. K., Zimmerman, J., Barajas, P., Cheuk, R., Gadrinab, C., Heller, C., Jeske, A., Koesema, E., Meyers, C. C., Parker, H., Prednis, L., Ansari, Y., Choy, N., Deen, H., Geralt, M., Hazari, N., Hom, E., Karnes, M., Mulholland, C., Ndubaku, R., Schmidt, I., Guzman, P., Aguilar-Henonin, L., Schmid, M., Weigel, D., Carter, D. E., Marchand, T., Risseeuw, E., Brogden, D., Zeko, A., Crosby, W. L., Berry , C. C., and Ecker, J. R. 2003. Genome-wide insertional mutagenesis of Arabidopsis thaliana. Science 301:653-657.

Ambrose, C., and Wasteneys, G. O. 2012. Nanoscale and geometric influences on the microtubule cytoskeleton in plants: Thinking inside and outside the box. Protoplasma, 249:69-76.

Ashby, J., Boutant, E., Seemanpillai, M., Sambade, A., Ritzenthaler, C., and Heinlein, M. 2006. Tobacco mosaic virus movement protein functions as a structural microtubule-associated protein. J. Virol. 80:8329-8344.

Beauchemin, C., Boutet, N., and Laliberté, J.-F. 2007. Visualization of the interaction between the precursors of $\mathrm{VPg}$, the viral protein linked to the genome of turnip mosaic virus, and the translation eukaryotic initiation factor iso 4E in planta. J. Virol. 81:775-782.

Brandner, K., Sambade, A., Boutant, E., Didier, P., Mely, Y., Ritzenthaler, C., and Heinlein, M. 2008. Tobacco mosaic virus movement protein interacts with green fluorescent protein-tagged microtubule end-binding protein 1. Plant Physiol. 147:611-623.

Buschmann, H., Fabri, C. O., Hauptmann, M., Hutzler, P., Laux, T., Lloyd, C. W., and Schäffner, A. R. 2004. Helical growth of the Arabidopsis mutant tortifolia1 reveals a plant-specific microtubule-associated protein. Curr. Biol. 14:1515-1521.

Cai, G. 2010. Assembly and disassembly of plant microtubules: Tubulin modifications and binding to MAPs. J. Exp. Bot. 61:623-626.

Cai, G., and Cresti, M. 2010. Microtubule motors and pollen tube growth-Still an open question. Protoplasma 247:131-143.

Caldo, R.A., Nettleton, D., and Wise, R. P. 2004. Interaction-dependent gene expression in Mla-specified response to barley powdery mildew. Plant Cell 16:2514-2528.
Charrasse, S., Mazel, M., Taviaux, S., Berta, P., Chow, T., and Larroque, C. 1995. Characterization of the cDNA and pattern of expression of a new gene over-expressed in human hepatomas and colonic tumors. Eur. J. Biochem. 234:406-413.

Cho, S.-Y., Cho, W. K., Choi, H.-S., and Kim, K.-H. 2012. Cis-acting element (SL1) of Potato virus $X$ controls viral movement by interacting with the NbMPB2Cb and viral proteins. Virology 427:166-176.

Chung, B. Y.-W., Miller, W. A., Atkins, J. F., and Firth, A. E. 2008. An overlapping essential gene in the Potyviridae. Proc. Natl. Acad. Sci. U.S.A 105:5897-5902.

Chuong, S. D. X., Franceschi, V. R., and Edwards, G. E. 2006. The cytoskeleton maintains organelle partitioning required for single-cell $\mathrm{C} 4$ photosynthesis in Chenopodiaceae species. Plant Cell 18:2207-2223.

Cole, C., Barber, J. D., and Barton, G. J. 2008. The Jpred 3 secondary structure prediction server. Nucleic Acids Res. 36:W197-W201. Published online.

Combet, C., Blanchet, C., Geourjon, C., and Deléage, G. 2000. NPS@: Network protein sequence analysis. Trends Biochem. Sci. 25:147-150.

Cotton, S., Grangeon, R., Thivierge, K., Mathieu, I., Ide, C., Wei, T., Wang, A., and Laliberté, J.-F. 2009. Turnip mosaic virus RNA replication complex vesicles are mobile, align with microfilaments, and are each derived from a single viral genome. J. Virol. 83:10460-10471.

Crowell, E. F., Bischoff, V., Desprez, T., Rolland, A., Stierhof, Y.-D., Schumacher, K., Gonneau, M., Höfte, H., and Vernhettes, S. 2009. Pausing of Golgi bodies on microtubules regulates secretion of cellulose synthase complexes in Arabidopsis. Plant Cell 21:1141-1154.

Deeks, M. J., Fendrych, M., Smertenko, A., Bell, K. S., Oparka, K., Cvrckova, F., Zarsky, V., and Hussey, P. J. 2010. The plant formin AtFH4 interacts with both actin and microtubules, and contains a newly identified microtubule-binding domain. J. Cell Sci. 123:1209-1215.

De Smet, I., Voss, U., Jürgens, G., and Beeckman, T. 2009. Receptor-like kinases shape the plant. Nat. Cell Biol. 11:1166-1173.

Drevensek, S., Goussot, M., Duroc, Y., Christodoulidou, A., Steyaert, S., Schaefer, E., Duvernois, E., Grandjean, O., Vantard, M., Bouchez, D., and Pastuglia, M. 2012. The Arabidopsis TRM1-TON1 interaction reveals a recruitment network common to plant cortical microtubule arrays and eukaryotic centrosomes. Plant Cell 24:178-191.

Dryková, D., Cenklová, V., Sulimenko, V., Volc, J., Dráber, P., and Binarová, P. 2003. Plant $\gamma$-tubulin interacts with $\alpha \beta$-tubulin dimers and forms membrane-associated complexes. Plant Cell 15:465-480.

Dufresne, P. J., Thivierge, K., Cotton, S., Beauchemin, C., Ide, C., Ubalijoro, E., Laliberté, J.-F., and Fortin, M. G. 2008. Heat shock 70 protein interaction with Turnip mosaic virus RNA-dependent RNA polymerase within virus-induced membrane vesicles. Virology 374:217-227.

Edgar, R. C., and Sjölander, K. 2004. COACH: Profile-profile alignment of protein families using hidden Markov models. Bioinformatics 20:13091318.

Ehrhardt, D. 2008. Straighten up and fly right-Microtubule dynamics and organization of non-centrosomal arrays in higher plants. Curr. Opin. Cell Biol. 20:107-116.

Gillespie, T., Boevink, P., Haupt, S., Roberts, A. G., Toth, R., Valentine, T., Chapman, S., and Oparka, K. J. 2002. Functional analysis of a DNAshuffled movement protein reveals that microtubules are dispensable for the cell-to-cell movement of Tobacco mosaic virus. Plant Cell 14:12071222

Guo, D., Spetz, C., Saarma, M., and Valkonen, J. P. T. 2003. Two potato proteins, including a novel RING finger protein (HIP1), interact with the potyviral multifunctional protein HCpro. Mol. Plant-Microbe Interact. 16:405-410.

Gutierrez, R., Lindeboom, J. J., Paredez, A. R., Emons, A. M. C., and Ehrhardt, D. W. 2009. Arabidopsis cortical microtubules position cellulose synthase delivery to the plasma membrane and interact with cellulose synthase trafficking compartments. Nat. Cell Biol. 11:797-806.

Hamada, T., Tominaga, M., Fukaya, T., Nakamura, M., Nakano, A., Watanabe, Y., Hashimoto, T., and Baskin, T. I. 2012. RNA processing bodies, peroxisomes, golgi bodies, mitochondria, and ER tubule junctions frequently pause at cortical microtubules. Plant Cell Physiol. 53:699-708

Harries, P. A., Schoelz, J. E., and Nelson, R. S. 2010. Intracellular transport of viruses and their components: Utilizing the cytoskeleton and membrane highways. Mol. Plant-Microbe Interact. 23:1381-1393.

Hawkins, T., Mirigian, M., Selcuk Yasar, M., and Ross, J. L. 2010. Mechanics of microtubules. J. Biomech. 43:23-30.

Huang, T. S., Wei, T., Laliberte, J. F., and Wang, A. 2010. A host RNA helicase-like protein, AtRH8, interacts with the potyviral genome-linked protein, VPg, associates with the virus accumulation complex, and is essential for infection. Plant Physiol. 152:255-266.

Karimi, M., Inzé, D., and Depicker, A. 2002. GATEWAY vectors for Agrobacterium-mediated plant transformation. Trends Plant Sci. 7:193-195.

Kelloniemi, J., Mäkinen, K., and Valkonen, J. P. T. 2006. A potyvirus- 
based gene vector allows producing active human S-COMT and animal GFP, but not human sorcin, in vector-infected plants. Biochimie, 88:505-513.

Kippert, F., and Gerloff, D. L. 2009. Highly sensitive detection of individual HEAT and ARM repeats with HHpred and COACH. PloS One 4:e7148.

Lechner, B., Rashbrooke, M. C., Collings, D. A., Eng, R. C., Kawamura, E., Whittington, A. T., and Wasteneys, G. O. 2012. The N-terminal TOG domain of Arabidopsis MOR1 modulates affinity for microtubule polymers. J. Cell Sci. 125:4812-4821.

Lupas, A., Dyke, M. Van, and Stock, J. 1991. Predicting coiled coils from protein sequences. Science 252:1162-1164.

Mathur, J., Mathur, N., Kernebeck, B., Srinivas, B. P., and Hülskamp, M. 2003. A novel localization pattern for an EB1-like protein links microtubule dynamics to endomembrane organization. Curr. Biol. 13:19911997.

McFarlane, H. E., Young, R. E., Wasteneys, G. O., and Samuels, A. L. 2008. Cortical microtubules mark the mucilage secretion domain of the plasma membrane in Arabidopsis seed coat cells. Planta 227:1363-1375.

Miller, S., and Krijnse-Locker, J. 2008. Modification of intracellular membrane structures for virus replication. Nat. Rev. Microbiol. 6:363-374.

Min, B.-E., Martin, K., Wang, R., Tafelmeyer, P., Bridges, M., and Goodin, M. 2010. A host-factor interaction and localization map for a plant-adapted Rhabdovirus implicates cytoplasm-tethered transcription activators in cell-to-cell movement. Mol. Plant-Microbe Interact. 23:1420-1432.

Ouko, M. O., Sambade, A., Brandner, K., Niehl, A., Peña, E., Ahad, A., Heinlein, M., and Nick, P. 2010. Tobacco mutants with reduced microtubule dynamics are less susceptible to TMV. Plant J. 62:829-839.

Pacheco, R., García-Marcos, A., Manzano, A., García de Lacoba, M., Camañes, G., García-Agustin, P., Díaz-Ruíz, J. R., and Tenllado, F. 2012. Comparative analysis of transcriptomic and hormonal responses to compatible and incompatible plant-virus interactions that lead to cell death. Mol. Plant-Microbe Interact. 25:709-723.

Peng, K., Radivojac, P., Vucetic, S., Dunker, A. K., and Obradovic, Z 2006. Length-dependent prediction of protein intrinsic disorder. BMC Bioinformatics 7:208.

Petrášek, J., and Schwarzerová, K. 2009. Actin and microtubule cytoskeleton interactions. Curr. Opin. Plant Biol. 12:728-734.

Pfaffl, M. W. 2001. A new mathematical model for relative quantification in real-time RT-PCR. Nucl. Acids Res. 29:e45-e45.

Qiao, F., Chang, X.-L., and Nick, P. 2010. The cytoskeleton enhances gene expression in the response to the harpin elicitor in grapevine. J. Exp. Bot. 61:4021-4031.

Rajamäki, M., Merits, A., Rabenstein, F., Andrejeva, J., Paulin, L., Kekarainen, T., Kreuze, J. F., Forster, R. L., and Valkonen, J. P. T. 1998. Biological, serological, and molecular differences among isolates of Potato A potyvirus. Phytopathology 88:311-321.

Rajamäki, M. L., Mäki-Valkama, T., Mäkinen, K. and Valkonen, J. P. T. 2004. Infection with potyviruses. Pages 68-91 in: Plant-pathogen interactions N. J. Talbot, ed. Blackwell Publishing, Sheffield, U.K.

Rajamäki, M.-L., and Valkonen, J. P. T. 2009. Control of nuclear and nucleolar localization of nuclear inclusion protein a of Picorna-like Potato virus A in Nicotiana species. Plant Cell 21:2485-2502.

Ratcliff, F., Martin-Hernandez, A. M., and Baulcombe, D. C. 2001. Tobacco rattle virus as a vector for analysis of gene function by silencing. Plant J. 25:237-245.

Ruggenthaler, P., Fichtenbauer, D., Krasensky, J., Jonak, C., and Waigmann, E. 2009. Microtubule-associated protein AtMPB2C plays a role in organization of cortical microtubules, stomata patterning, and tobamovirus infectivity. Plant Physiol. 149:1354-1365.

Schoelz, J. E., Harries, P. A., and Nelson, R. S. 2011. Intracellular transport of plant viruses: Finding the door out of the cell. Mol. Plant 4:813-831.

Shi, F.-M., Yao, L.-L., Pei, B.-L., Zhou, Q., Li, X.-L., Li, Y., and Li, Y.-Z. 2009. Cortical microtubule as a sensor and target of nitric oxide signal during the defence responses to Verticillium dahliae toxins in Arabidopsis. Plant Cell Environ. 32:428-438.

Shoji, T., Narita, N. N., Hayashi, K., Asada, J., Hamada, T., Sonobe, S., Nakajima, K., and Hashimoto, T. 2004. Plant-specific microtubuleassociated protein SPIRAL2 is required for anisotropic growth in Arabidopsis. Plant Physiol. 136:3933-3944.

Slep, K. C., and Vale, R. D. 2007. Structural basis of microtubule plus end tracking by XMAP215, CLIP-170, and EB1. Mol. Cell 27:976-991.

Soitamo, A. J., Jada, B., and Lehto, K. 2011. HC-Pro silencing suppressor significantly alters the gene expression profile in tobacco leaves and flowers. BMC Plant Biol. 11:68.
Stamatakis, A., Hoover, P., and Rougemont, J. 2008. A rapid bootstrap algorithm for the RAxML Web servers. Syst. Biol. 57:758-771.

Söding, J. 2005. Protein homology detection by HMM-HMM comparison. Bioinformatics 21:951-960.

Takagi, S., Takamatsu, H., and Sakurai-Ozato, N. 2009. Chloroplast anchoring: Its implications for the regulation of intracellular chloroplast distribution. J. Exp. Bot. 60:3301-3310.

Thiel, H., and Varrelmann, M. 2009. Identification of Beet necrotic yellow vein virus $\mathrm{P} 25$ pathogenicity factor-interacting sugar beet proteins that represent putative virus targets or components of plant resistance. Mol. Plant-Microbe Interact. 22:999-1010.

Thivierge, K., Cotton, S., Dufresne, P. J., Mathieu, I., Beauchemin, C., Ide, C., Fortin, M. G., and Laliberté, J.-F. 2008. Eukaryotic elongation factor $1 \mathrm{~A}$ interacts with Turnip mosaic virus RNA-dependent RNA polymerase and VPg-Pro in virus-induced vesicles. Virology 377:216-225.

Vijayapalani, P., Maeshima, M., Nagasaki-Takekuchi, N., and Miller, W. A. 2012. Interaction of the trans-frame potyvirus protein P3N-PIPO with host protein PCaP1 facilitates potyvirus movement. PLoS Pathog. 8:e1002639. Published online.

Vuorinen, A. L., Gammelgård, E., Auvinen, P., Somervuo, P., Dere, S., and Valkonen, J. P. T. 2010. Factors underpinning the responsiveness and higher levels of virus resistance realized in potato genotypes carrying virus-specific R genes. Ann. Appl. Biol. 157:229-241.

Vuorinen, A. L., Kelloniemi, J., and Valkonen, J. P. T. 2011. Why do viruses need phloem for systemic invasion of plants? Plant Sci. 181:355-363

Wei, T., Huang, T.-S., McNeil, J., Laliberté, J.-F., Hong, J., Nelson, R. S., and Wang, A. 2010a. Sequential recruitment of the endoplasmic reticulum and chloroplasts for plant potyvirus replication. J. Virol. 84:799809.

Wei, T., Zhang, C., Hong, J., Xiong, R., Kasschau, K. D., Zhou, X., Carrington, J. C., and Wang, A. 2010b. Formation of complexes at plasmodesmata for potyvirus intercellular movement is mediated by the viral protein P3N-PIPO. PLoS Pathog. 6:e1000962. Published online.

Whelan, S., and Goldman, N. 2001. A general empirical model of protein evolution derived from multiple protein families using a maximum-likelihood approach. Mol. Biol. Evol. 18:691-699.

Wright, K. M., Cowan, G. H., Lukhovitskaya, N. I., Tilsner, J., Roberts, A. G, Savenkov, E. I., and Torrance, L. 2010. The N-terminal domain of PMTV TGB1 movement protein is required for nucleolar localization, microtubule association, and long-distance movement. Mol. PlantMicrobe Interact. 23:1486-1497.

Yao, L., Zhou, Q., Pei, B., and Li, Y. 2011. Hydrogen peroxide modulates the dynamic microtubule cytoskeleton during the defence responses to Verticillium dahliae toxins in Arabidopsis. Plant Cell Environ. 34:15861598.

Yao, M., Wakamatsu, Y., Itoh, T. J., Shoji, T., and Hashimoto, T. 2008. Arabidopsis SPIRAL2 promotes uninterrupted microtubule growth by suppressing the pause state of microtubule dynamics. J. Cell Sci. 121:2372-2381.

Zamyatnin, A. A., Jr, Solovyev, A. G., Bozhkov, P. V., Valkonen, J. P. T, Morozov, S. Y., and Savenkov, E. I. 2006. Assessment of the integral membrane protein topology in living cells. Plant J. 46:145-154.

Zhang, X., Henriques, R., Lin, S.-S., Niu, Q.-W., and Chua, N.-H. 2006. Agrobacterium-mediated transformation of Arabidopsis thaliana using the floral dip method. Nat. Prot. 1:641-646.

Zhu, H., Hong, J., Ye, R., Chen, J., Yu, S., and Adams, M.J. 2001. Sequence analysis shows that Ribgrass mosaic virus Shanghai isolate (RMV-Sh) is closely related to Youcai mosaic virus. Arch. Virol. 146:1231-1238.

\section{AUTHOR-RECOMMENDED INTERNET RESOURCES}

Coach Protein sequence analysis software: www.drive5.com/lobster

DisProt Predictor of Intrinsically Disordered Regions website: www.dabi.temple.edu/disprot/predictor.php

EMBL-EBI ClustalW2 program: www.ebi.ac.uk/Tools/msa/clustalw2

EMBnet Coils program: www.ch.embnet.org/software/COILS_form.html

Jnet Jpred3 server and software: www.compbio.dundee.ac.uk/www-jpred

Max Planck Institute for Developmental Biology HHpred software: toolkit.tuebingen.mpg.de/hhpred

The NPS@ (Network Protein Sequence @nalysis) server: www.bioinf.manchester.ac.uk/dbbrowser/bioactivity/NPS2.html

RAxML BlackBox server and software: phylobench.vital-it.ch/raxml-bb

Salk Institute Genomic Analysis Laboratory database: www.signal.salk.edu/interactome/PPIN1.html

Sol Genomics Network database: solgenomics.net 